\title{
Evaluation of Binjharpuri cattle of India in the native tract
}

\author{
S. K. Dash ${ }^{1 *}$, B. P. Sethi ${ }^{2}$ and P. K. Rao ${ }^{1}$ \\ ${ }^{1}$ Department of Animal Breeding and Genetics, Orissa Veterinary College Orissa University of Agriculture and \\ Technology, Bhubaneswar, 751003, Orissa, India. \\ ${ }^{2}$ Department of Animal Husbandry and Veterinary Services, Government of Orissa, India.
}

Accepted 4 February, 2013

\begin{abstract}
Physical characterization of Binjharpuri cattle was done under a project, funded by Orissa Livestock Resources Development Society (OLRDS). This was done by collecting information on herd's structure, prevailing management practices, body conformation, production and reproduction performance of recently registered breed of cattle viz. Binjharpuri and socio-economic profile of the farmers rearing these cattle. Average body weight, height at withers, body length, heart girth, punch girth, tail length and horn length in males were $254.71 \pm 7.32 \mathrm{~kg}, 121.4 \pm 1.76,126.32 \pm 2.32,144.2 \pm 2.32,143.2 \pm 2.31,95.7 \pm 3.23$ and $21.17 \pm 2.86 \mathrm{~cm}$, respectively. The corresponding figures in females were $207.05 \pm 5.32 \mathrm{~kg}, 107.3 \pm 2.16$, $115.1 \pm 1.14,136.2 \pm 2.84,146.3 \pm 3.5,97.9 \pm 3.71$ and $12.7 \pm 1.31 \mathrm{~cm}$, respectively.
\end{abstract}

Key words: Characterization, native tract, body conformation, performance.

\section{INTRODUCTION}

Cattle are the most popular species among all livestock in India. Livestock continue to be the prime livelihood of the vast majority of the rural households along with agriculture. Livestock keeping has been the major source of supplementary income for rural households next to agriculture. Livestock production has always been an integral part of the rural livelihood systems in Orissa. Around $80 \%$ of marginal or small as well as landless farmers in the State of Orissa possess livestock of some species or the other. However, cattle head the preference list. Crop production in Orissa is almost dependent on work animals such as bullocks for farm power; and the primary objective of the farming community in the breeding of cattle, consequently, continues to be the production of work animals.
After the mechanization in agriculture, Orissa is among the few remaining states in the country, which is still almost dependent on work animals for farm power. Therefore, demand of farm families towards making work animals still keeps its importance in breeding management of cattle and buffalo.

Out of the 34 recognized breeds of cattle in India, 'Binjharpuri' is the one with native tract in Orissa, which still exists in its purest form after doing much artificial insemination through the process of crossbreeding. This explains why stakeholders prefer to maintain unique qualities of these cattle population in its native tract. This type of cattle is not only popular in yielding handful amount of milk in low input system of rearing, but also proves its worth in agricultural operations in the native its 
tract. The present study aims to identify the natural habitat of this breed of cattle and to evaluate production and reproduction potential as well as its physical characteristics.

\section{MATERIALS AND METHODS}

The present study was a part of technical programme of the Project funded by OLRDS. During the present study, information on 3230 animals of all age groups belonging to 458 farm families was collected through massive survey covering 48 villages. The information on body confirmation was collected by actual measurements; information on production, reproduction and socio economic profile was collected through interactions and structure scheduled questionnaires developed by National Bureau of Animal Genetic Resources (NBAGR) with little modifications. The data collected were statistically analyzed based on Harvey (1990).

\section{Native tract}

Binjharpuri cattle are seen in their classical form in Jajpur District and some areas in adjoining districts of Kendrapara and Bhadrak in Orissa. The area comprises mainly coastal plain and some saline zones. Heavy concentrations of Binjharpuri cattle are seen in Binjharpur, Bari, Sujanpur and Dasarathpur area of Jajpur District. The name of the breed can be traced back to its natural habitat. The native tract of the breed is distributed over $85^{\circ} 40^{\prime}$ to $86^{\circ} 44$ East longitude and $20^{\circ} 43^{\prime}$ to $21^{\circ} 10^{\prime}$ North latitude spread over an area of $3690 \mathrm{~km}^{2}$. The minimum and maximum temperature of $11.2^{\circ} \mathrm{C}$ and $48.5^{\circ} \mathrm{C}$, respectively and average rainfall of $1580.9 \mathrm{~mm}$ in the region explains the climatic conditions of the area.

\section{Physical characteristics}

Binjharpuri is medium sized, horned, strong, dual type docile cattle with good posture. Bulls look very strong, vigorous with welldeveloped hump, penis, naval flap and dewlap. The hump, neck and some regions of the face and back are black in colour irrespective of the coat colour of the males. Bulls have majestic gait. Cows are proportionate and compacted with graceful appearance. The pin bones are distinct and quite wide apart compared with the body confirmation. The milk vein is prominent but medium in appearance. Calves with light brown or grayish colour develop to whitish colour at adult age. Vulva is comparatively larger and drooping. Long tail is an important feature of this breed of cattle, which almost touches the ground. It is tapering towards tip with voluminous switch. The ears are short and dewlap is thin, small and soft.

\section{Management practices}

About $70 \%$ of the sheds are made up of thatched roof with kutcha floor. The four sides of the house are covered with bamboo sticks, palm leaves or coconut leaves, making it well ventilated. Around $20 \%$ of the sheds have walls with clay and mud, with the upper portion of the walls open. In $5 \%$ cases, a part of the verandah of the dwelling house of the owner serves as shed for these animals. Usually, one female member of the family takes care of the milch cows as well as newborn calves.

Cows, bullocks and calves are tied with plastic or jute ropes individually during night in the shed. During morning, all the animals are tied in the outskirt of the owners' houses. They milk their cows at this place. They give feed like rice bran, kitchen wastes etc. and water either at the time of or after milking in the same place and let their animals loose for grazing. In summer season, all the animals are tied outside the shed even at night. Usually in the morning, working bullocks are provided with 'Kurchi', a mixture of rice bran, wheat bran, kitchen waste and some amount of rice warmed with water. Then, these are taken for ploughing or carting. All other animals fill their stomach with vegetations available in harvested field, pasture and beside roads. In most cases, all the animals of a village are taken to grazing by hired labour when agriculture fields are filled with crops. However, all animals are provided with clean drinking water in the afternoon after returning from grazing. In some cases, the animals are supplied with preserved post harvested dried legume plants (hay) in some places. No concentrate feed is given to the animals. Usually, the owners of Binjharpuri cattle do not prefer artificial insemination. Very few owners though opt for artificial insemination; in majority of cases, the local bull manages to render effective service to produce its offspring. The animals of 4 to 5 villages gather at pastureland for grazing. The most strong and stout bull in the herd crosses the cow in oestrus at grazing. One to two bulls are normally seen in a herd of 50 to 100 cows. Though Binjharpuri cattle are not seasonal breeders, the onset of oestrus is more common in rainy and winter seasons.

\section{RESULTS AND DISCUSSION}

The means with standard errors for body weights and conformation traits of Binjharpuri cattle (males and females) are given in Table 1. The average adult weights of males and females were found to be $254.71 \pm 7.32$ and $207.05 \pm 5.32 \mathrm{~kg}$, respectively. The males were taller than females. The average values of height at withers were $121.4 \pm 1.76$ and $107.3 \pm 2.16 \mathrm{~cm}$ in males and females, respectively, which were found to be higher than other cattle populations of Orissa like Motu, Ghumsari and Khariar as reported by Swain (2003), Sahoo (1989) and Dhal (2007), and Punganur breed of Andhra Pradesh (Planner, 2003). The body length of males was found to be longer $(126.32 \pm 2.32 \mathrm{~cm})$ than that of females $(115.1 \pm 1.14 \mathrm{~cm})$. Body length of Binjharpuri cattle was higher than that of Khariar cattle (Dhal, 2007) and Mottu cattle (Swain, 2003) of Orissa. The average values for chest girth and punch girth of Binjharpuri cattle seemed to be higher compared to other cattle of Orissa (Swain, 2003). Female Binjharpuri cattle had shorter horn $(12.7 \pm 1.31 \mathrm{~cm})$ than that of males $(21.17 \pm 2.86 \mathrm{~cm})$. The average tail length was $95.7 \pm 3.23 \mathrm{~cm}$ in males and $97.9 \pm 3.71 \mathrm{~cm}$ in females.

Binjharpuri heifers attain their puberty at an average age of $912.32 \pm 11.23$ days and drop the first calf at $1230.73 \pm 12.42$ days. Throughout their lives, these animals produce 9.26 calves with average calving interval of $409.62 \pm 6.72$ days and gestation length of $282.32 \pm 2.61$ days, which is at par with the findings of Sarkhel (2001) (Table 2).

Average milk yield was around $4 \mathrm{~L}$ per day in two milking without supplementation of concentrate. Average fat and SNF\% of the milk were recorded as 4.4 and $8.5 \%$, respectively. Cows are docile and female member of the 
Table 1. Body weight and body measurements of Binjharpuri cattle.

\begin{tabular}{|c|c|c|c|c|c|c|c|c|c|c|}
\hline & Sex & BW (kg) & $\mathrm{HW}(\mathrm{cm})$ & $\mathrm{BL}(\mathrm{cm})$ & HG (cm) & $P G(\mathrm{~cm})$ & TL (cm) & $\mathrm{HeL}(\mathrm{cm})$ & HoL (cm) & EL (cm) \\
\hline \multirow{2}{*}{ Birth } & $M$ & $19.42 \pm 0.67$ & $58.32 \pm 1.23$ & $46.41 \pm 1.12$ & $57.62 \pm 2.10$ & $58.62 \pm 2.36$ & $32.22 \pm 0.42$ & $18.23 \pm 0.28$ & - & $12.86 \pm 0.18$ \\
\hline & $\mathrm{F}$ & $17.83 \pm 0.82$ & $56.62 \pm 1.15$ & $45.37 \pm 1.14$ & $55.83 \pm 1.81$ & $58.43 \pm 1.18$ & $32.28 \pm 0.32$ & $17.83 \pm 0.31$ & - & $12.84 \pm 0.21$ \\
\hline \multirow{2}{*}{3 month } & $M$ & $41.76 \pm 1.12$ & $75.67 \pm 2.13$ & $69.67 \pm 1.76$ & $78.62 \pm 2.03$ & $79.57 \pm 1.86$ & $46.36 \pm 0.78$ & $25.44 \pm 0.62$ & - & $13.42 \pm 0.24$ \\
\hline & $\mathrm{F}$ & $39.21 \pm 1.23$ & $73.82 \pm 1.18$ & $69.67 \pm 1.76$ & $78.62 \pm 2.03$ & $79.57 \pm 1.86$ & $46.36 \pm 0.78$ & $25.44 \pm 0.62$ & - & $13.31 \pm 0.28$ \\
\hline \multirow{2}{*}{6 month } & $M$ & $56.65 \pm 3.78$ & $84.32 \pm 2.42$ & $78.23 \pm 2.23$ & $86.42 \pm 1.62$ & $87.12 \pm 2.13$ & $56.78 \pm 1.02$ & $29.82 \pm 0.62$ & - & $15.56 \pm 0.41$ \\
\hline & $\mathrm{F}$ & $51.20 \pm 3.16$ & $82.16 \pm 1.98$ & $75.23 \pm 1.86$ & $83.56 \pm 2.11$ & $84.33 \pm 2.16$ & $55.63 \pm 1.12$ & $27.37 \pm 0.43$ & - & $15.21 \pm 0.38$ \\
\hline \multirow{2}{*}{12 month } & $M$ & $98.72 \pm 4.23$ & $90.38 \pm 3.22$ & $91.26 \pm 3.34$ & $105.62 \pm 4.21$ & $105.73 \pm 4.23$ & $72.37 \pm 2.34$ & $33.35 \pm 0.42$ & $2.43 \pm 0.21$ & $17.26 \pm 0.52$ \\
\hline & $\mathrm{F}$ & $93.25 \pm 3.26$ & $88.56 \pm 1.2$ & $89.67 \pm 1.65$ & $103.56 \pm 1.86$ & $103.32 \pm 1.72$ & $73.62 \pm 0.86$ & $30.72 \pm 0.42$ & $1.43 \pm 0.21$ & $16.86 \pm 0.37$ \\
\hline \multirow{2}{*}{ Adult ( $>2$ yr) } & $M$ & $254.71 \pm 7.32$ & $121.4 \pm 1.76$ & $126.32 \pm 2.32$ & $144.2 \pm 2.32$ & $143.2 \pm 2.31$ & $95.7 \pm 3.23$ & $44.7 \pm 1.2$ & $21.17 \pm 2.86$ & $20.53 \pm 0.23$ \\
\hline & $\mathrm{F}$ & $207.05 \pm 5.32$ & $107.3 \pm 2.16$ & $115.1 \pm 1.14$ & $136.2 \pm 2.84$ & $146.3 \pm 3.5$ & $97.9 \pm 3.71$ & $40.1 \pm 0.2$ & $12.7 \pm 1.31$ & $19.14 \pm 0.26$ \\
\hline
\end{tabular}

BW, Body weight; TL, tail length; HW, height at withers; HeL, head length; BL, body length; HoL, horn length; HG, heart girth; EL, ear length; PG, punch girth.

Table 2. Reproduction traits of Binjharpuri cattle.

\begin{tabular}{|c|c|c|}
\hline $\mathbf{S} / \mathbf{N}$ & Traits & Observation \\
\hline 1 & Age at puberty (days) & $912.32 \pm 11.23$ \\
\hline 2 & Oestrus cycle duration (days) & 21 \\
\hline 3 & Oestrus duration (hrs) & 24 \\
\hline 4 & Age at $1^{\text {st }}$ mating (days) & $948.42 \pm 14.56$ \\
\hline 5 & Age at $1^{\text {st }}$ calving (days) & $1230.73 \pm 12.42$ \\
\hline 6 & Age at $2^{\text {nd }}$ calving (days) & $1648.65 \pm 18.43$ \\
\hline 7 & Interval for calving to conception (days) & $126.25 \pm 3.41$ \\
\hline 8 & Calving interval (days) & $409.62 \pm 6.72$ \\
\hline 9 & Gestation length (days) & $282.32 \pm 2.61$ \\
\hline 10 & Life time no. of calvings & 9.26 \\
\hline
\end{tabular}

family usually milks lactating cows. The highest lactational yield was recorded as $1338.28 \mathrm{~L}$ with an average lactation length of $308.36 \pm 4.23$ days in the fourth lactation. The dairy performance of
Binjharpuri cattle in terms of lactation is presented in Table 3. 
Table 3. Dairy performance of Binjharpuri cattle in different lactations.

\begin{tabular}{lcccc}
\hline \multirow{2}{*}{ Dairy performance } & \multicolumn{4}{c}{ Lactation } \\
\cline { 2 - 5 } & I & II & III & IV \\
\hline Daily milk yield (Its) & $3.23 \pm 0.14$ & $3.35 \pm 0.13$ & $4.23 \pm 0.16$ & $4.34 \pm 0.11$ \\
Peak milk yield (Its) & 4.14 & 4.32 & 5.12 & 5.05 \\
Days to reach peak yield & 62.3 & 64.3 & 58.3 & 52.4 \\
Lactation length (days) & $273.73 \pm 3.26$ & $296.62 \pm 3.75$ & $302.23 \pm 4.23$ & $308.36 \pm 4.23$ \\
Lactation milk yield (Its) & 916.45 & 993.68 & 1278.43 & 1338.28 \\
Fat \% & 4.41 & 4.40 & 4.36 & 4.41 \\
SNF \% & 8.58 & 8.54 & 8.56 & 8.53 \\
Dry period (days) & 126.23 & 113.13 & 107.51 & 101.25 \\
\hline
\end{tabular}

\section{ACKNOWLEDGEMENT}

The authors acknowledge the contribution of OLRDS for giving funds for the present study.

\section{REFERENCES}

Dhal BK (2007). Genetic performance of khariar cattle in its native tract" M.V.Sc. Thesis, OUAT, Bhubaneswar.

Harvey WR (1990). User's Guide for LSMLMW, PC-2 Version, Mixed Model Least Squares and Maximum Likelihood Computer Program, Mimeograph, Columbus, Ohio, USA.

Planner (2003). Celebrating Diversity: Livestock and Poultry Breeds of Andhra Pradesh.
Sahoo SP (1989). 'Characteristics and performance of Ghumsari cattle'. M.V.Sc. Thesis OUAT, Bhubaneswar.

Sarkhel BC (2001). 'Characterization of Nimari breed of cattle'. J.N.K.V.V. Technical Bulletin: DRS/2001/09 1-46.

Swain KT (2003). Performance and conformation of Motu cattle found in Malkangiri District of Orissa.'M.V.Sc. Thesis, OUAT, Bhubaneswar. 